Check for updates

Nuffield Department of Primary Care Health Sciences, University of Oxford, UK

2 St Thomas' Hospital, London, UK

3 Somerville College, University of Oxford, Oxford, UK

4 St John's College, University of Oxford, Oxford, UK

5 Fluid Dynamics of Disease Transmission Laboratory, Massachusetts Institute of Technology, Cambridge, MA, USA

Correspondence to: L. Bourouiba lbouro@mit.edu

Cite this as: BMJ 2020;370:m3223 http://dx.doi.org/10.1136/bmj.m3223 Published: 25 August 2020

\section{Two metres or one: what is the evidence for physical distancing in covid-19?}

\section{Rigid safe distancing rules are an oversimplification based on outdated science and experiences of past viruses, argue Nicholas $\mathbf{R}$ Jones and colleagues}

\author{
Nicholas R Jones, Zeshan U Qureshi, ${ }^{2}$ Robert J Temple, ${ }^{3}$ Jessica P J Larwood, ${ }^{4}$ Trisha Greenhalgh, \\ Lydia Bourouiba ${ }^{5}$
}

Physical distancing is an important part of measures to control covid-19, but exactly how far away and for how long contact is safe in different contexts is unclear. Rules that stipulate a single specific physical distance (1 or 2 metres) between individuals to reduce transmission of SARS-CoV-2, the virus causing covid-19, are based on an outdated, dichotomous notion of respiratory droplet size. This overlooks the physics of respiratory emissions, where droplets of all sizes are trapped and moved by the exhaled moist and hot turbulent gas cloud that keeps them concentrated as it carries them over metres in a few seconds. ${ }^{12}$ After the cloud slows sufficiently, ventilation, specific patterns of airflow, and type of activity become important. Viral load of the emitter, duration of exposure, and susceptibility of an individual to infection are also important.

Instead of single, fixed physical distance rules, we propose graded recommendations that better reflect the multiple factors that combine to determine risk. This would provide greater protection in the highest risk settings but also greater freedom in lower risk settings, potentially enabling a return towards normality in some aspects of social and economic life.

\section{Origins of 2 metre rule}

The study of how droplets are emitted during speech or more forcefully when coughing or sneezing began in the 19th century, with scientists typically collecting samples on glass or agar plates. ${ }^{3}$ In 1897 , for example, Flugge proposed a 1-2 $\mathrm{m}$ safe distance based on the distance over which sampled visible droplets contained pathogens. ${ }^{4}$ In the 1940 , visual documentation of these emissions became possible with close-up still imaging of sneezing, coughing, or talking (fig 1). ${ }^{5}$ A study in 1948 of haemolytic streptococci spread found $65 \%$ of the 48 participants produced large droplets only, fewer than $10 \%$ of which travelled as far as $5^{1 / 2}$ feet $(1.7 \mathrm{~m}) .{ }^{6}$ However, in $10 \%$ of participants, haemolytic streptococci were collected $9^{1 / 2}$ feet $(2.9 \mathrm{~m})$ away. Despite limitations in the accuracy of these early study designs, especially for longer ranges, the observation of large droplets falling close to a host reinforced and further entrenched the assumed scientific basis of the 1-2 $\mathrm{m}$ distancing rule. ${ }^{2}$ 


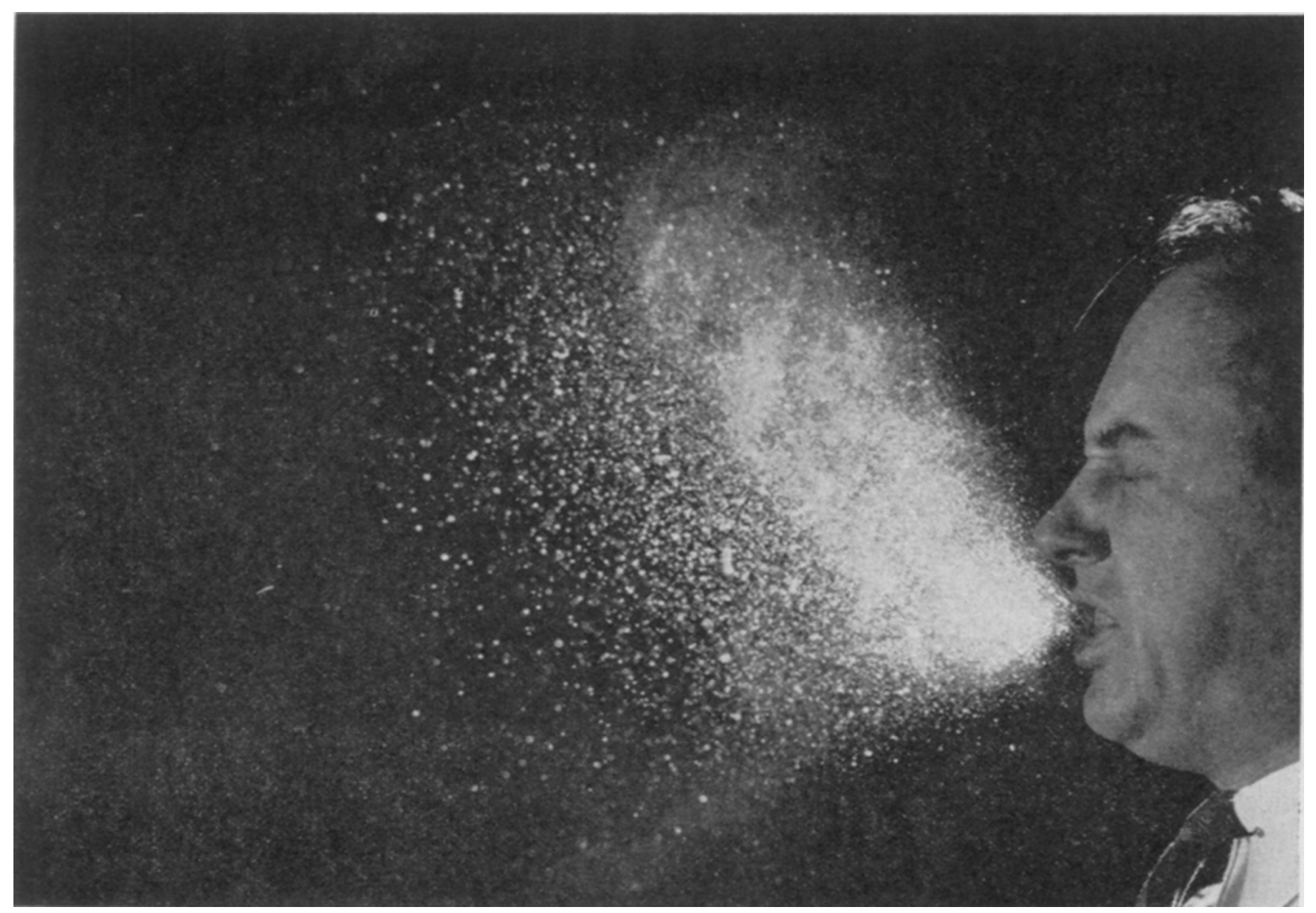

Fig 1 | Short range still imaging of stages of sneezing, revealing the liquid droplets from the 1942 Jennison experiment. ${ }^{5}$ Reproduced with permission

Yet eight of the 10 studies in a recent systematic review showed horizontal projection of respiratory droplets beyond $2 \mathrm{~m}$ for particles up to $60 \mu \mathrm{m} .^{7}$ In one study, droplet spread was detected over 6-8 m (fig 2). ${ }^{28}$ These results suggest that SARS-CoV-2 could spread beyond
1-2 $\mathrm{m}$ in a concentrated packet through coughs or sneezes. ${ }^{2}$ In recent related viral outbreaks, such as SARS-CoV-1, MERS-CoV, and Avian flu, multiple studies reported suspected spread beyond $2 \mathrm{~m} . .^{910}$ 


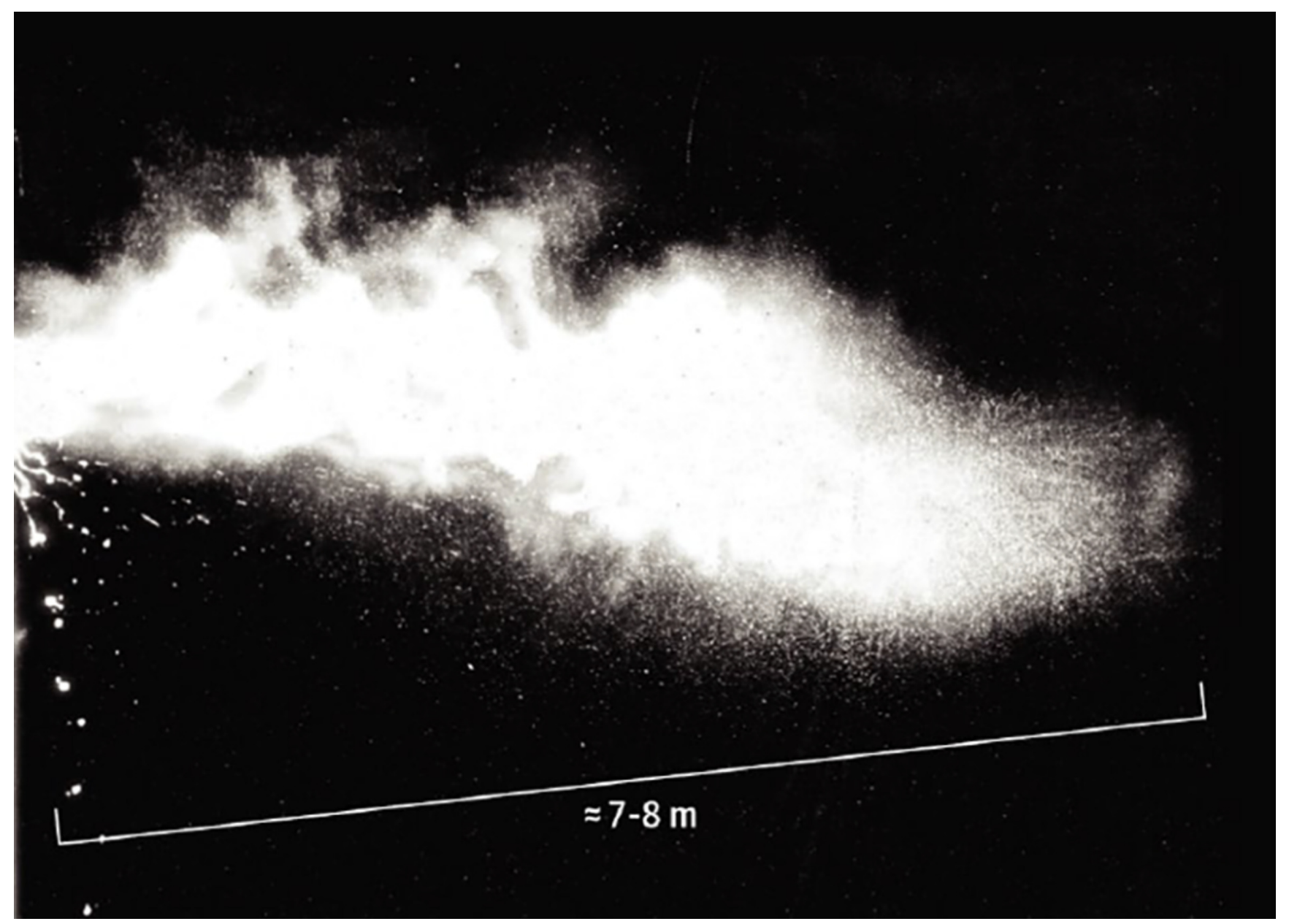

Fig 2 | Long range video imaging over $8 \mathrm{~m}$ of the multiphase turbulent cloud (gas cloud containing liquid droplets of all sizes) from natural human violent emission such as a sneeze, revealing a range of the cloud, and its droplet concentrated payload, of up to 7-8 $\mathrm{m}$. Reproduced with permission from Bourouiba ${ }^{2}$

\section{Droplet size, droplet spread}

The 1-2 $\mathrm{m}$ rule is based on a longstanding framework which dichotomises respiratory droplets into two sizes, large and small. The size of a droplet is thought to determine how far it will travel from the infected person. According to studies by Wells, emitted large droplets fall through the air more quickly than they evaporate and land within a 1-2 metre range. ${ }^{11}$ Small droplets (later called aerosols or airborne droplets), typically invisible to the naked eye, evaporate more quickly than they fall. Without airflow, they cannot move far, remaining in the exhaler's vicinity. With airflow they can spread along greater distances.

While conceptually useful up to a point, this dichotomy framework overlooks contemporary science about respiratory exhalations. ${ }^{12}$

Droplets exist across a continuum of sizes. Contextual factors such as exhaled air and ambient airflow are extremely important in determining how far droplets of all sizes travel. Without exhaled airflow, the largest droplets would travel furthest (1-2 m), while the small ones would encounter high resistance (drag) and stay close to the source. When accounting for the exhaled airflow, clouds of small droplets can travel beyond $2 \mathrm{~m}$ in the air, and even large droplets have enhanced range. ${ }^{12}$

\section{Airborne particle spread of SARS-CoV-2}

Diseases that can be transmitted by airborne particles, such as measles and varicella, can travel much further, and in concentrated clouds, than those transmitted by large droplets, which drop from clouds more quickly. They can therefore expose others rapidly and at greater distance ${ }^{213}$ and may need different public health measures, including extended physical distancing. Laboratory studies also suggest SARS-CoV-1, SARS-CoV-2, and MERS-CoV viral particles are stable in airborne samples, with SARS-CoV-2 persistent for longest (up to 16 hours). ${ }^{14} 15$

In a literature search for studies using air sampling techniques to detect viral particles surrounding covid-19 patients, we found nine studies in hospital and two in community settings. Seven of the hospital studies reported at least one airborne sample tested positive for SARS-CoV-2, though the proportion of positive samples across studies ranged between $2 \%$ and $64 \%{ }^{16-22}$ Only two reported positive results in relation to distance from an infected patient (one at $2 \mathrm{~m}^{18}$ and another at $\geq 4 \mathrm{~m}$ in the corridor ${ }^{17}$ ). Of the two hospital studies that did not find SARS-CoV-2 particles in air samples, ${ }^{23} 24$ one collected positive swab samples from ventilation units in the patient's room, which is consistent with airborne droplet spread. ${ }^{23}$

Neither community study reported positive air samples, although one collected specimens up to 17 days after covid-19 carriers had left the room ${ }^{25}$ and the other did not report time of sampling since 
cleaning or sampling distance from the infected person. ${ }^{26}$ These negative studies thus fall substantially short of proving that airborne spread does not occur.

Only two of the airborne sampling studies directly measured whether SARS-CoV-2 in the samples remained infectious, rather than just analysing for the presence of viral RNA. ${ }^{1821}$ No viable virus was found in either, though one found signs of viral ability to replicate. ${ }^{18}$ Of note, no study found viable virus on surface swabs.

These studies were small, observational, and heterogeneous in terms of setting, participants, sample collection, and handling methods. They were prone to recall bias (few people can accurately recall how close they came to others when asked to remember some time later). Overall, these studies seem to support the possibility of airborne spread of SARS-CoV-2, but they do not confirm that there is a risk of disease transmission.

\section{Force of emission, ventilation, exposure time}

Breathing out, singing, coughing, and sneezing generate warm, moist, high momentum gas clouds of exhaled air containing respiratory droplets. This moves the droplets faster than typical background air ventilation flows, keeps them concentrated, and can extend their range up to 7-8 m within a few seconds. ${ }^{128}$

These findings from fluid dynamic studies help explain why at one choir practice in the US, a symptomatic person infected at least 32 other singers, with 20 further probable cases, despite physical distancing. ${ }^{27}$ Other indoor case clusters have been reported within fitness gyms, boxing matches, call centres, and churches, where people might sing, pant, or talk loudly. ${ }^{28-30}$ Interestingly, there have been few reports of outbreaks on aeroplanes, ${ }^{31}$ which may reflect current low volume of passengers, lack of contact tracing, or relatively low risk because speaking is limited. Although publication bias is likely (events linked to outbreaks are more likely to be reported than events where no outbreak occurred), well documented stories of outbreaks demand a scientific explanation.

The heavy panting from jogging and other sports produces violent exhalations with higher momentum than tidal breathing, closer to coughs in some instances. This increases the distance reached by the droplets trapped within the exhaled cloud and supports additional distancing during vigorous exercise. ${ }^{2}$ However, respiratory droplets tend to be more quickly diluted in well aerated outdoor settings, reducing transmission risk (a preprint from Japan reports an 18.7-fold higher risk of transmission in indoor environments than outdoors). ${ }^{28}$

Specific airflow patterns, and not just average ventilation and air changes, within buildings are also important in determining risk of exposure and transmission. A case report from an outbreak at a restaurant in China described 10 people within three families infected over one hour, at distances of up to $4.6 \mathrm{~m}$ and without direct physical contact. The pattern of transmission was consistent with the transient indoor localised ventilation airflow pattern. ${ }^{32}$
Few studies have examined how airflow patterns influence viral transmission; most studies report (if anything) only average indoor ventilation rates. Neglecting variation in localised air flow within a space oversimplifies and underestimates risk modelling. In homogeneous flow, patterns are known to emerge in occupied indoor spaces that depend on air conditioning, ventilation system or location, occupancy of the space, air recirculation, and filtration.

Though it is widely assumed that duration of exposure to a person with covid-19 influences transmission risk (studies of contact tracing, for example, consider thresholds of 5-15 minutes beyond which risk increases ${ }^{334}$ ), we are not aware of studies that quantified this variable.

\section{Distance and transmission risk}

The UK's Scientific Advisory Group for Emergencies (SAGE) estimates that the risk of SARS-CoV-2 transmission at $1 \mathrm{~m}$ could be 2-10 times higher than at $2 \mathrm{~m} .{ }^{35} \mathrm{~A}$ systematic review commissioned by the World Health Organization attempted to analyse physical distancing measures in relation to coronavirus transmission. ${ }^{36}$ Physical distancing of $<1 \mathrm{~m}$ was reported to result in a transmission risk of $12.8 \%$, compared with $2.6 \%$ at distances $\geq 1 \mathrm{~m}$, supporting physical distancing rules of $1 \mathrm{~m}$ or more. The review's limitations should be noted. Not all distances were explicit in the original studies; some were estimated by the review authors. Different distances were used to categorise social contact in different studies (1.8 $\mathrm{m}$ was considered close in one study but distant in another, for example), yet these were pooled within the same analysis. The summary relied heavily on data from the SARS-CoV-1 and MERS outbreaks and only partially accounted for environmental confounders.

\section{More nuanced model}

Environmental influences are complex and are likely to be mutually reinforcing. This is shown, for example, in meat packing plants, where outbreaks have been attributed to the combination of high levels of worker contagion, poor ventilation, cramped working conditions, background noise (which leads to shouting), and low compliance with mask wearing. ${ }^{37}$ Similar compound risk situations might occur in other crowded, noisy, indoor environments, such as pubs or live music venues.

Physical distancing rules would be most effective if they reflected graded levels of risk. Figure 3 presents a guide to how transmission risk may vary with setting, occupancy level, contact time, and whether face coverings are worn. These estimates apply when everyone is asymptomatic. In the highest risk situations (indoor environments with poor ventilation, high levels of occupancy, prolonged contact time, and no face coverings, such as a crowded bar or night club) physical distancing beyond $2 \mathrm{~m}$ and minimising occupancy time should be considered. Less stringent distancing is likely to be adequate in low risk scenarios. People with symptoms (who should in any case be self-isolating) tend to have high viral load and more frequent violent respiratory exhalations. 


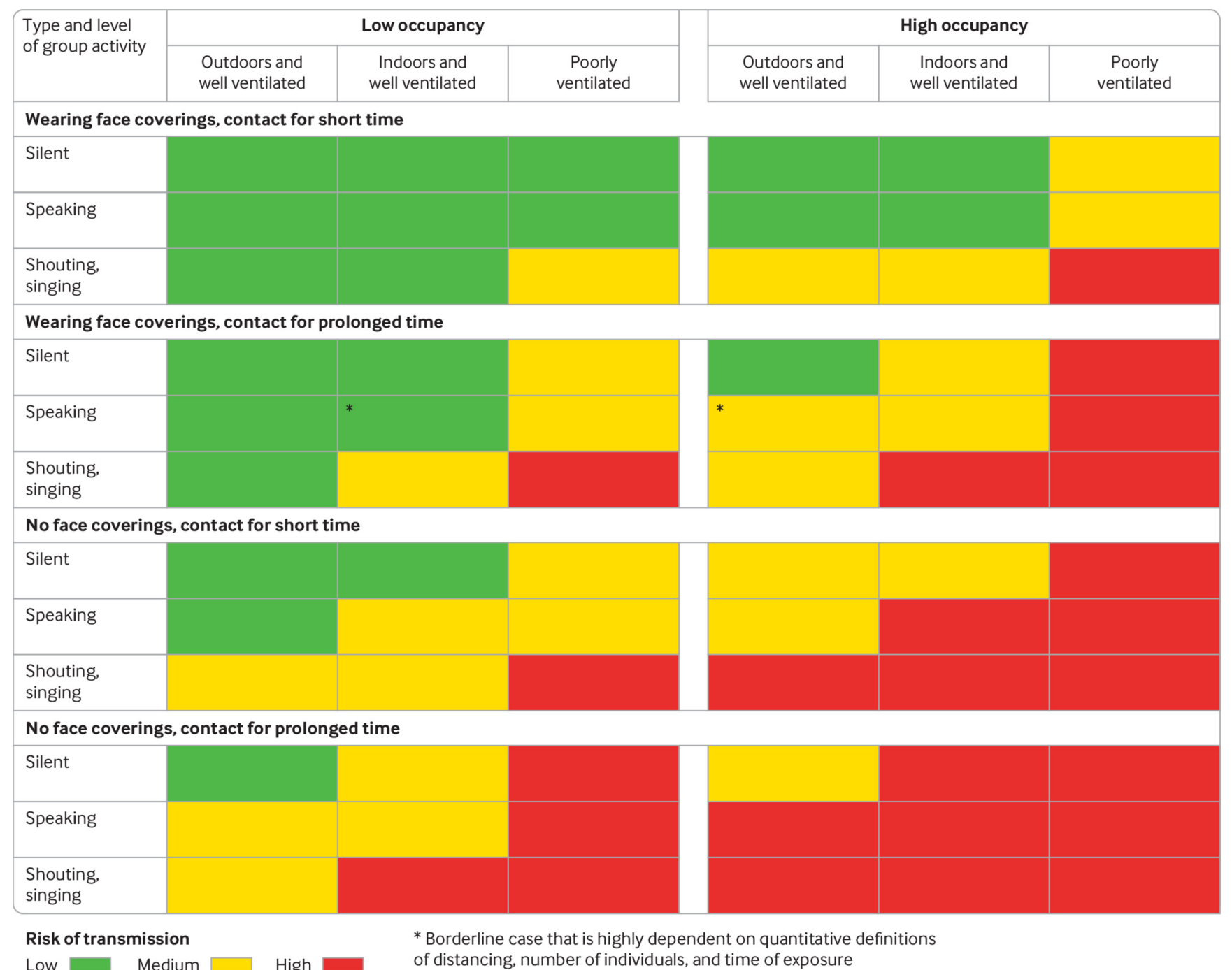

Fig 3 | Risk of SARS-CoV-2 transmission from asymptomatic people in different settings and for different occupation times, venting, and crowding levels (ignoring variation in susceptibility and viral shedding rates). Face covering refers to those for the general population and not high grade respirators. The grades are indicative of qualitative relative risk and do not represent a quantitative measure. Other factors not presented in these tables may also need to be taken into account when considering transmission risk, including viral load of an infected person and people's susceptibility to infection. Coughing or sneezing, even if these are due to irritation or allergies while asymptomatic, would exacerbate risk of exposure across an indoor space, regardless of ventilation

The levels of risk in fig 3 are relative not absolute, especially in relation to thresholds of time and occupancy, and they do not include additional factors such as individuals' susceptibility to infection, shedding level from an infected person, indoor airflow patterns, and where someone is placed in relation to the infected person. Humidity may also be important, but this is yet to be rigorously established.

Further work is needed to extend our guide to develop specific solutions to classes of indoor environments occupied at various usage levels. Urgent research is needed to examine three areas of uncertainty: the cut-off duration of exposures in relation to the indoor condition, occupancy, and level of viral shedding (5-15 minute current ad-hoc rules), which does not seem to be supported by evidence; the detailed study of airflow patterns with respect to the infected source and its competition with average venting; and the patterns and properties of respiratory emissions and droplet infectivity within them during various physical activities.
Physical distancing should be seen as only one part of a wider public health approach to containing the covid-19 pandemic. It needs to be implemented alongside combined strategies of people-air-surface-space management, including hand hygiene, cleaning, occupancy and indoor space and air managements, and appropriate protective equipment, such as masks, for the setting.

\section{Key messages}

Current rules on safe physical distancing are based on outdated science Distribution of viral particles is affected by numerous factors, including air flow

Evidence suggests SARS-CoV-2 may travel more than $2 \mathrm{~m}$ through activities such as coughing and shouting

Rules on distancing should reflect the multiple factors that affect risk, including ventilation, occupancy, and exposure time

Contributors and sources: This article was adapted from a rapid review undertaken as part of the Oxford COVID-19 Evidence Service (https://www.cebm.net/covid-19/what-is-the-evidence-to-supportthe-2-metre-social-distancing-rule-to-reduce-covid-19-transmission/); all authors contributed to its development and approved the final manuscript. 
Patient and public involvement: Three members of the public provided feedback on the article. They strongly supported the need for an in-depth analysis of physical distancing and thought our summary figure was helpful in presenting factors that influence categories of risk. Specific feedback led to additional discussion points addressing transmission risk in complex settings such as the meat packing industry and with exercise.

Competing interests: We have read and understood BMJ policy on declaration of interests and have no relevant interests to declare.

Provenance and peer review: Not commissioned; externally peer reviewed.

We thank Nia Roberts, who helped with identifying relevant research underpinning this article.

1 Bourouiba L, Dehandschoewercker E, Bush John WM. Violent expiratory events: on coughing and sneezing. J Fluid Mech 2014;745:537-63. doi: 10.1017/jfm.2014.88.

2 Bourouiba L. Turbulent gas clouds and respiratory pathogen emissions: potential implications for reducing transmission of COVID-19. JAMA 2020. [Epub ahead of print.] doi: 10.1001/jama.2020.4756. pmid: 32215590

3 Papineni RS, Rosenthal FS. The size distribution of droplets in the exhaled breath of healthy human subjects. J Aerosol Med 1997;10:105-16. doi: 10.1089/jam.1997.10.105. pmid: 10168531

4 Flugge C. Uber luftinfection. Z Hyg Infektionskr 1897;25:179-224.

5 Turner CE, Jennison MW, Edgerton HE. Public health applications of high-speed photography Am J Pub Health 1941 Apr:319-24.

6 Hamburger $\mathrm{M}$, JrRobertson $\mathrm{OH}$. Expulsion of group A hemolytic streptococci in droplets and droplet nuclei by sneezing, coughing and talking. Am J Med 1948;4:690-701. doi: 10.1016/S0002-9343(48)90392-1. pmid: 18856764

7 Bahl P, Doolan C, de Silva C, Chughtai AA, Bourouiba L, Maclntyre CR. Airborne or droplet precautions for health workers treating COVID-19?] Infect Dis 2020: doi: 10.1093/infdis/jiaa189. pmid: 32301491

8 Bourouiba L. Images in clinical medicine. A sneeze. N Engl J Med 2016;375:. doi: 10.1056/NEJMicm1501197. pmid: 27557321

9 Yu ITS, Li Y, Wong TW, etal. Evidence of airborne transmission of the severe acute respiratory syndrome virus. N Engl J Med2004;350:1731-9. doi: 10.1056/NEJMoa032867. pmid: 15102999

10 Tang JW, Li Y, Eames I, Chan PK, Ridgway GL. Factors involved in the aerosol transmission of infection and control of ventilation in healthcare premises. J Hosp Infect 2006;64:100-14. doi: 10.1016/j.jhin.2006.05.022. pmid: 16916564

11 Wells WF. Airborne contagion and air hygiene: an ecological study of droplet infections. JAMA 1955;159:90.

12 Borak J. Airborne transmission of covid-19. Occup Med (Lond) 2020;70:297-9. doi: 10.1093/occmed/kqaa080. pmid: 32476011

13 Shiu EYC, Leung NHL, Cowling BJ. Controversy around airborne versus droplet transmission of respiratory viruses: implication for infection prevention. Curr Opin Infect Dis 2019;32:372-9. doi: 10.1097/QC0.0000000000000563. pmid: 31259864

14 Fears AC, Klimstra WB, Duprex P, etal. Persistence of severe acute respiratory syndrome coronavirus 2 in aerosol suspensions. Emerg Infect Dis 2020;26. doi: 10.3201/eid2609.201806. pmid: 32568661

15 van Doremalen N, Bushmaker T, Morris DH, etal. Aerosol and surface stability of SARS-CoV-2 as compared with SARS-CoV-1. N Engl J Med 2020;382:1564-7. doi: 10.1056/NEJMc2004973. pmid: 32182409

16 Liu Y, Ning Z, Chen Y, etal. Aerodynamic analysis of SARS-CoV-2 in two Wuhan hospitals. Nature 2020;582:557-60. doi: 10.1038/s41586-020-2271-3. pmid: 32340022

17 Guo Z-D, Wang Z-Y, Zhang S-F, etal. Aerosol and surface distribution of severe acute respiratory syndrome coronavirus 2 in hospital wards, Wuhan, China, 2020. Emerg Infect Dis 2020;26:1583-91. doi: 10.3201/eid2607.200885. pmid: 32275497

18 Santarpia JL, Rivera DN, Herrena V. Transmission potential of SARS-CoV-2 in viral shedding observed at the University of Nebraska Medical Center. medRxiv 2020.2003.2023.20039446. [Preprint.] doi: 10.1101/2020.03.23.20039446

19 Ding Z, Qian H, Xu B, et al. Toilets dominate environmental detection of SARS-CoV-2 virus in a hospital. medRxiv 2020.04.03.20052175. [Preprint.] doi: 10.1101/2020.04.03.20052175

20 Chia PY, Coleman KK, Tan YK, et al. Detection of air and surface contamination by severe acute respiratory syndrome 2 coronavirus 2 (SARS-CoV-2) in hospital rooms of infected patients. medRxiv 2020.03.29.20046557. [Preprint.] doi: 10.1101/2020.03.29.20046557.

21 Zhou J, Otter J, Price J, et al. Investigating SARS-CoV-2 surface and air contamination in an acute healthcare setting during the peak of the COVID-19 pandemic in London. medRxiv 2020.05.24.20110346 [Preprint.] doi: 10.1101/2020.05.24.20110346

$22 \mathrm{MaJ}, \mathrm{QiX}$, Chen H, et al. Exhaled breath is a significant source of SARS-CoV-2 emission. medRxiv 2020.05.31.20115154.[Preprint.] doi: 10.1101/2020.05.31.20115154

23 Ong SWX, Tan YK, Chia PY, etal. Air, surface environmental, and personal protective equipment contamination by severe acute respiratory syndrome coronavirus 2 (SARS-CoV-2) from a symptomatic patient. JAMA 2020. [Epub ahead of print.] doi: 10.1001/jama.2020.3227. pmid: 32129805

24 Wu S, Wang Y, Jin X, Tian J, Liu J, Mao Y. Environmental contamination by SARS-CoV-2 in a designated hospital for coronavirus disease 2019. Am J Infect Control 2020;48:910-4. doi: 10.1016/j.ajic.2020.05.003. pmid: 32407826
25 Yamagishi T. Environmental sampling for severe acute respiratory syndrome coronavirus 2 (SARS-CoV-2) during a coronavirus disease (COVID-19) outbreak aboard a commercial cruise ship. medRxiv2020.05.02.20088567. [Preprint.] doi: 10.1101/2020.05.02.20088567

26 Döhla M, Wilbring G, Schulte B, et al. SARS-CoV-2 in environmental samples of quarantined households. medRxiv 2020.05.28.20114041. [Preprint.] doi: 10.1101/2020.05.28.20114041

27 Hamner L, Dubbel P, Capron I, etal. High SARS-CoV-2 attack rate following exposure at a choir practice-Skagit County, Washington, March 2020. MMWR Morb Mortal Wkly Rep 2020;69:606-10. doi: 10.15585/mmwr.mm6919e6. pmid: 32407303

28 Nishiura H, Oshitani H, Kobayashi T, et al. Closed environments facilitate secondary transmission of coronavirus disease 2019 (COVID-19). medRxiv 2020.02.28.20029272. doi: 10.1101/2020.02.28.20029272

29 Leclerc QJ, Fuller NM, Knight LE, Funk S, Knight GMCMMID COVID-19 Working Group. What settings have been linked to SARS-CoV-2 transmission clusters? Wellcome Open Res 2020;5:83. doi: 10.12688/wellcomeopenres.15889.2. pmid: 32656368

30 Park SY, Kim YM, Yi S, etal. Coronavirus disease outbreak in call center, South Korea. Emerg Infect Dis 2020;26:1666-70. doi: 10.3201/eid2608.201274. pmid: 32324530

31 Yang N, Shen Y, Shi C, et al. In-flight transmission cluster of covid-19: a retrospective case series. medRxiv 2020.03.28.20040097 [Preprint.] doi: 10.1101/2020.03.28.20040097

32 Li Y, Qian H, Hang J, et al. Evidence for probable aerosol transmission of SARS-CoV-2 in a poorly ventilated restaurant. medRxiv 2020.04.16.20067728. [Preprint.] doi: 10.1101/2020.04.16.20067728

33 Cheng H-Y, Jian S-W, Liu D-P, et al. High transmissibility of covid-19 near symptom onset. medRxiv 2020.03.18.20034561. [Preprint.] doi: 10.1101/2020.03.18.20034561

34 Doung-ngern P, Suphanchaimat R, Panjangampatthana A, et al. Associations between wearing masks, washing hands, and social distancing practices, and risk of COVID-19 infection in public: a cohort-based case-control study in Thailand. medRxiv 2020.06.11.20128900. [Preprint.] doi: 10.1101/2020.06.11.20128900.

35 Scientific Advisory Group on Emergencies. Transmission of SARS-CoV-2 and mitigating measures. https://assets.publishing.service.gov.uk/government/uploads/system/uploads/attachment_data/file/892043/S0484_Transmission_of_SARS-CoV-2_and_Mitigating_Measures.pdf

36 Chu DK, Akl EA, Duda S, Solo K, Yaacoub S, Schünemann HJCOVID-19 Systematic Urgent Review Group Effort (SURGE). Physical distancing, face masks, and eye protection to prevent person-to-person transmission of SARS-CoV-2 and COVID-19: a systematic review and meta-analysis. Lancet2020;395:1973-87. doi: 10.1016/S0140-6736(20)31142-9. pmid: 32497510

37 Dyal JW, Grant MP, Broadwater K, etal. COVID-19 among workers in meat and poultry processing facilities - 19 States, April 2020. MMWR Morb Mortal Wkly Rep 2020;69. doi: 10.15585/mmwr.mm6918e3. pmid: 32379731

This article is made freely available for use in accordance with BMJ's website terms and conditions for the duration of the covid-19 pandemic or until otherwise determined by BMJ. You may use, download and print the article for any lawful, non-commercial purpose (including text and data mining) provided that all copyright notices and trade marks are retained. 